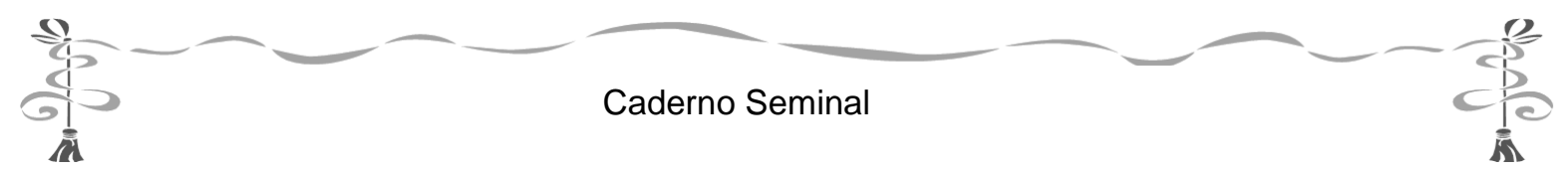

\title{
MANUAL DE PLE/PL2: DIÁLOGO EM PERSPECTIVA
}

\author{
MANUAL PLE/PL2: DIALOGUE IN PERSPECTIVE
}

Maria D'Ajuda Alomba Ribeiro ${ }^{44}$

\section{Resumo}

O objetivo deste trabalho é apresentar algumas dificuldades encontradas pelos alunos na aprendizagem de língua portuguesa como língua estrangeira (doravante PLE), partindo da ideia de que os alunos possuem algumas crenças quanto ao processo de ensino/aprendizagem. Os alunos acreditam no manual didático utilizado pelo professor, como ferramenta norteadora que ajuda expor os conteúdos e outras técnicas nas aulas. Dentre essas estratégias metodológicas podemos destacar: música, filmes, diálogos, representação da realidade, entre outros. Com essa diversidade os alunos se sentirão mais motivados e aprendizagem poderá ter mais resultados.

Palavras chave: Ensino de línguas. Manual. TICs

\section{Abstract}

This paper aims at presenting some difficulties found by the students in the learning of portuguese as a foreign language (henceforth PFL), from the conception that the students have some beliefs about the process of teaching/learning. The students believe in the teaching manual used by the teacher, as a guidance tool which helps on showing the contents and other techniques in the classes. Among these methodological strategies we can highlight: music, movies, dialogs, representation of the reality, and so on. With that diversity the students will feel more motivated and the learning will be able to be successful.

Keywords: Language teaching. Manual. TICs.

\section{Introdução}

Atualmente, temos no Brasil muitas universidades que trabalham o ensino de PLE e fazem convênio com universidades estrangeiras, estimulando os intercâmbios para a ampliação do quadro de falantes da língua portuguesa e conhecedores da língua portuguesa e cultura brasileira. Contudo, a busca por materiais eficientes no ensino de PLE nos remete a um problema que decorre desde os primórdios dessa prática de ensino no Brasil. Os primeiros manuais que foram elaborados para o ensino de PLE mostram uma visão diferenciada do ensino de uma língua estrangeira que se tem atualmente. O primeiro manual didático do ensino de PLE no Brasil, segundo Pacheco (2006, p. 72) foi criado em 1957, "advindo do empreendedorismo de professores e de linguistas".

Nesse período, os materiais e métodos eram muito diferentes dos que se têm hoje, pois o ensino de PLE ainda não tinha formulação de ensino de uma língua

${ }^{44}$ Universidade Estadual de Santa Cruz- UESC - dajudaalomba@hotmail.com

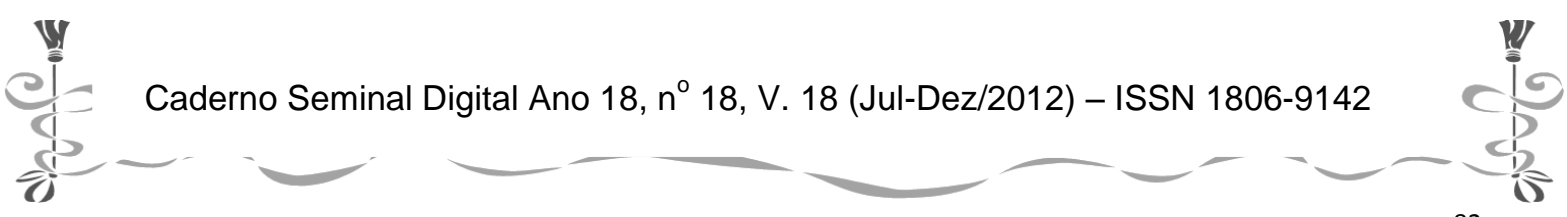




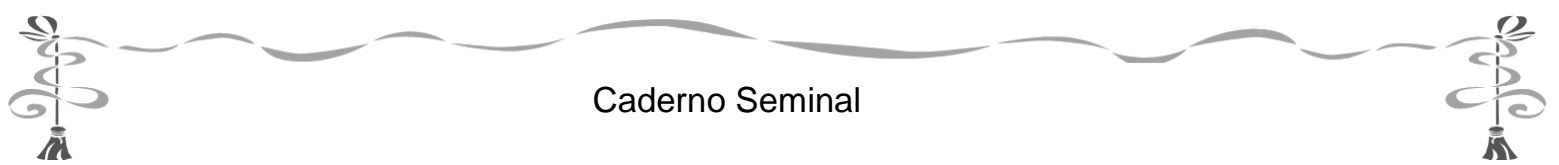

estrangeira, nesse momento e porque não dizer até hoje em alguns cursos, o ensino de PLE é ensinado da mesma maneira que se ensina o Português como Língua materna. Entre as décadas de 70 e 80 o ensino de uma língua estrangeira era baseado na repetição de diálogos que aproximariam os falantes estrangeiros da língua em estudo.

A discussão acerca do manual para falantes de outras línguas tem se mostrado mais recorrente, à medida que são dotados novos olhares, mais diversificados e outra forma de representação que buscaram incorporar questões voltadas para novas reflexões pedagógicas. Essa perspectiva enfatiza a importância de observar o manual didático mais recente levando em consideração o aluno como sujeito no processo ensino-aprendizagem.

Assim, pensar em uma abordagem feita nos manuais, de modo geral, torna-se insuficiente, uma vez que esse é o único material de que dispõe o professor na sala de aula. Todavia, grande parte do conteúdo proposto para o ensino de PLE/PL2 ainda segue a orientação tradicional, voltando-se para estruturas gramaticais e vocabulário e sem haver uma preocupação com as necessidades que levaram o indivíduo a querer aprender outra língua.

Como analisam Abrahão e Barcelos (2006), o ensino é uma atividade pessoal e coletiva, pois cada professor possui diferentes crenças, e agem de acordo com elas. A partir do momento em que passam a acreditar em determinadas coisas, automaticamente agirá de forma com o que acredita. Sendo assim, deve ser crítico o suficiente para observar se essa crença é adequada, para o ensino de seus alunos, e nem sempre uma boa técnica de ensino é a melhor para o processo de aprendizagem.

Pensando de outra forma, o manual deve servir não só de apoio, mas como veículo de uma abordagem produtiva permeando o implícito cultural entre os discursos e as várias linguagens. Dessa maneira, muito bem salienta O’ Neill (Apud MORITA, 1990) quando corrobora em dizer que nenhum livro é tão hermético que não permita que o professor faça suas adaptações e crie alternativas para outras atividades necessárias. Por outro lado, o manual alivia a tarefa planejada pelo professor de PLE/PL2, pois os que são apresentados implicitamente têm noção de pressupostos teóricos sobre língua, linguagem, ensinar e aprender uma língua estrangeira.

Nessa ótica, a depender dos motivos que levaram o aluno a optar por aprender aquela língua estrangeira, o professor será guiado a instrumentalizar uma metodologia voltada para o aluno-alvo, como também, entender a relação da prática, da intencionalidade do sujeito e do que se pode falar a depender de com que se fala (RODRIGUES, 2005).

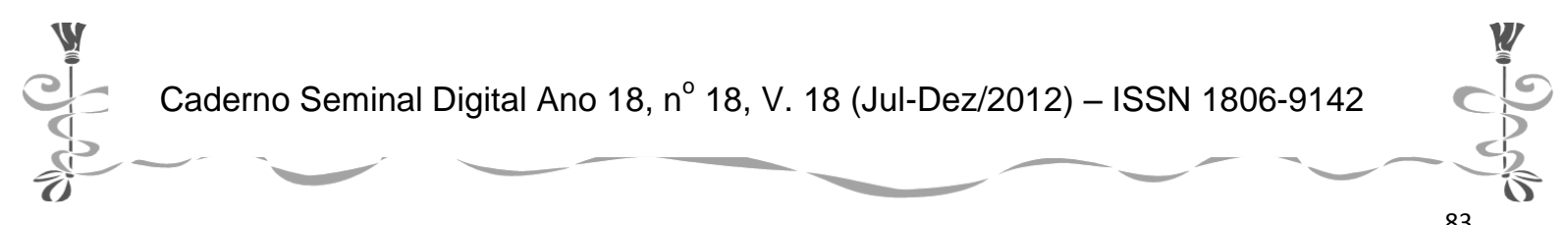




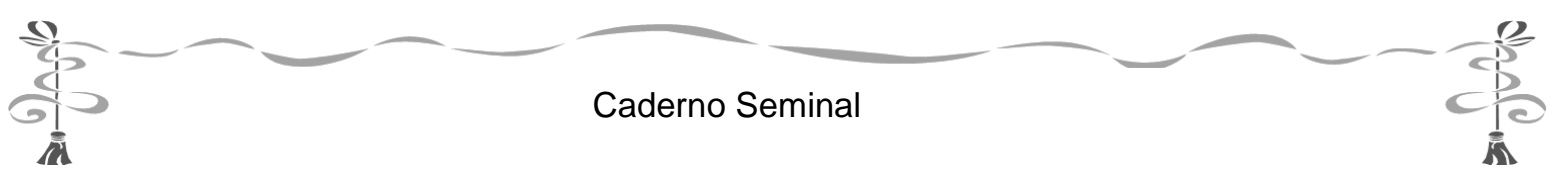

As novas tecnologias e ensino de línguas: o manual em questão

O manual é fundamental no processo de ensino/aprendizagem de uma língua estrangeira. Manual, do latim manus, significa algo que se pode manusear. Como se refere Tormenta (Apud TAVARES, 2008, p. 09), "se considerarmos a etimologia da palavra, verificamos tratar-se de algo que pode ser manuseável facilmente". Podemos considerar o manual como um material com uma estrutura definida e com objetivo de dar eficácia ao processo de ensino-aprendizagem. Segundo Choppin (Apud TAVARES, 2008, p.09), os manuais são os transmissores do saber de uma disciplina, veiculando um programa previamente estabelecido e com uma progressão bem definida.

Com o advento das tecnologias vivemos a uma verdadeira explosão de suportes de ensino informatizados que achávamos que o manual seria indispensável, é ao contrário, o manual continua sendo o suporte de aprendizagem mais utilizado, esse resiste a todas as inovações tecnológicas que estão aparecendo. O mercado de trabalho exige do indivíduo o mínimo de conhecimento no requisito informática, ligar e desligar um computador, saber reconhecer as mídias digitais, ou seja, ter domínio sobre a máquina. Não distante do tempo presente, o sujeito histórico por vezes fora dominado por ideologias disseminadas em seu contexto social. Atualmente, esse mesmo sujeito se vê dominado por um avanço tecnológico. Não descartamos a hipótese de que o manual em certos casos utiliza dessas novas tecnologias para manter-se no auge da modernidade, fazendo-se acompanhar de outros suportes, sejam informatizados, áudio ou vídeo. (FUENTE Apud TAVARES).

Nesse novo momento histórico-social, o espaço escolar não deve e, nem mesmo, pode estar distante de tais mudanças. A aproximação com as tecnologias reforça a garantia de uma qualidade educacional mais interativa. A escola tem por necessidade integrar o uso das TICs a esse novo momento de inovação social, que requer uma efetiva mudança ligada à construção do processo/aprendizagem.

\begin{abstract}
A natureza de incorporação às mídias digitais de linguagens e meios convencionais de comunicação (áudio, vídeo, animação, material impresso...), de uso consolidado antes do advento e da disseminação dos computadores, evidencia a necessidade de um planejamento que considere as características específicas de suas linguagens e potencialidades tecnológicas, propiciando a criação de uma sinergia para a concepção e realização de ações educacionais inovadoras (SCHÖN 1997, p. 87).
\end{abstract}

Nesse panorama, o professor/mediador que usa as TICs tende a fomentar práticas pedagógicas mais acessíveis, partindo de aulas mais interativas. Porém essa inovação nem sempre é favorável para o processo. O professor que está habituado aos manuais que muitas deles são atividades meramente reprodutoras de práticas engessadas, permeadas pelo medo de reconfigurar a própria prática e se aventurar

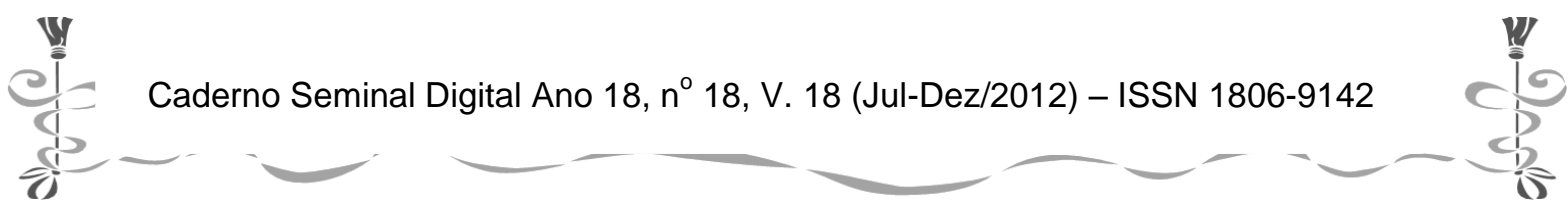




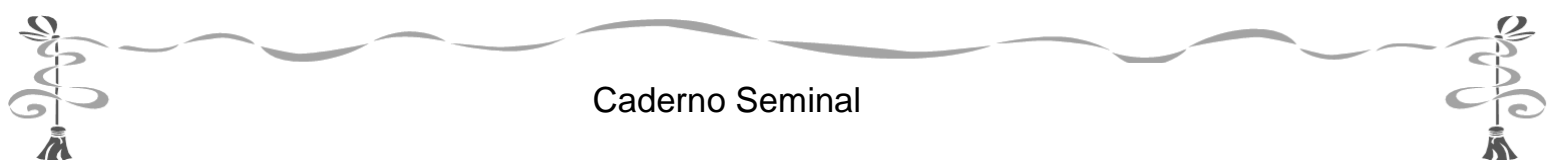

em um universo desconhecido, sem, por vezes, favorecer o desempenho de atitudes motivacionais. E isso muitas vezes é perceptível não só nos manuais de português como língua estrangeira, como também nos manuais de língua materna.

Assim, os vários setores sociais têm buscado se adaptar às mudanças pelas quais passam o mundo contemporâneo. E nesse momento, emerge o processo de construção identitária em interface com as novas tecnologias, "recontextualizando o papel político da escola (...) numa perspectiva de construção do conhecimento de forma dialética e multidimensional" (MOTA, 2004, p. 41). Dessa forma, com as mudanças paradigmáticas, todo o sujeito passa pelo caminho da assimilação e acomodação desta nova experiência, a qual permeia a descoberta dos novos modelos e consequentemente os manuais, sobretudo de PLE/PL2. É refletindo sobre essas mudanças que o professor assegura o direito de línguas de desenvolver o mais possível sua capacidade criativa (GOMES DE MATOS, 1994).

Entretanto, para muitos professores é mais fácil usar o manual impresso. As TICs são vistas como instrumentos irrelevantes, porque o uso destes recursos pode causar certo desconforto advindo do medo, sobretudo no que concerne à substituição do professor por uma "máquina". Ressaltamos que de forma alguma as TICs vão tirar o valor dos meios tradicionais. (HUOT, 1989, p.14). Mesmo com toda essa tecnologia não se pode imaginar um aluno sem manuais. Esses devem ser produzidos e usados de forma criativa, coerente e coesa com a realidade de cada região.

\section{A interface do manual no ensino de PLE}

No percurso dos tempos verifica-se que o manual não se limita à sua função de meio facilitador de transmissão de conhecimentos dentro do âmbito científico. $O$ manual pode refletir um sistema político ao "veicular a ideologia dominante" (BRITO Apud TAVARES, 2008: 09), uma visão do mundo e da sociedade, uma situação econômica, refletindo a realidade da época. Para tanto, os manuais têm que dar respostas a outras necessidades. Não devemos pensar como um mero transmissor de conhecimento e sim com o objetivo de desenvolver capacidades e competências. A garantia do manual visa um maior sucesso do processo de ensino/aprendizagem, de modo que não podemos deixar de lado alguma reflexão sobre os diferentes tipos de manuais, as suas funções e o papel num processo de interação e interlocução do português como língua estrangeira.

Cunningsworth (Apud RAMOS \& ROSELLI, 2008) defendem que o material bom é aquele que pode ser usado com a classe toda, com pequenos grupos e também individualmente, pois os alunos precisam ser atendidos tanto como indivíduos quanto como membros de um grupo. Sendo assim, a sala deve privilegiar momentos de aprendizagem individual e outros grupos. Isso porque em alguns momentos em as explicações e os atendimentos podem ser generalizados, e outros estritamente individualmente, e outras de preferência em pares ou em grupos. E por essa razão,

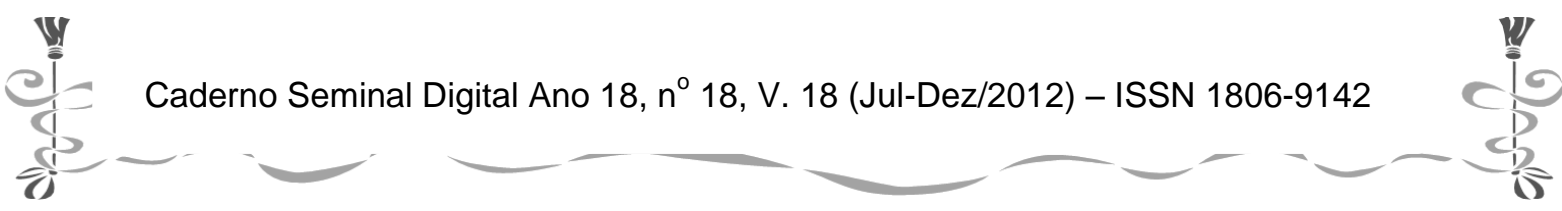




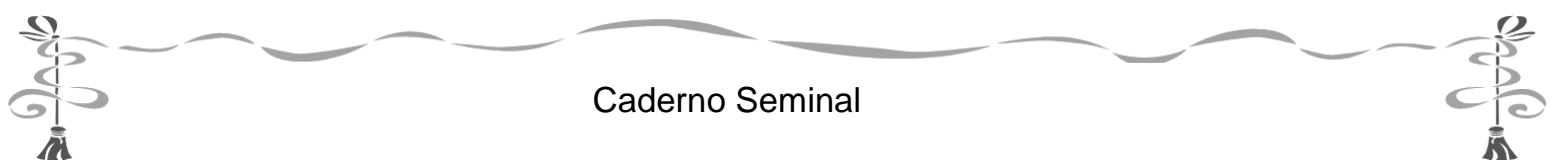

que o professor ao usar o manual tem de estar atento a essas idiossincrasias da aula de PLE.

O autor ressalta a importância do curso, as necessidades e as expectativas devem ser bem definidas, levando em consideração a idade e a língua materna do aluno.

Na concepção desse autor, ao escolher o manual em relação ao conteúdo linguístico, devemos examiná-lo acerca do tema. Os temas têm relevância e significação para um aprendiz privilegiando o seu crescimento intelectual. Almeida Filho (1992) discute a importância em atender as fantasias do aprendiz. Para isso o material deve tratar de assuntos que os estimulam e interage com sua vida.

Outro elemento importante é a função. Muitos livros não conseguem desvincular as funções da gradação gramatical, esquecendo-se de que na comunicação real as necessidades são outras. Contudo, não devemos esquecer os aspectos linguísticos servem para a compreensão, discussão e relatos orais e escritos e como estes se sistematizam. As habilidades linguísticas devem ser analisadas se estão de acordo com os objetivos do curso e determinar se alguma habilidade deva ser privilegiada em detrimento de outra. Claro é que essas divisões são contempladas pelas questões pedagógicas. Entretanto, precisamos esclarecer que as atividades comunicativas que envolvem mais de uma habilidade devem receber uma atenção especial, pois a comunicação na vida real é feita utilizando-se de varias habilidades simultaneamente. É importante que a sala de aula, na medida do possível, enfatize atividades que interagem diversas habilidades simultaneamente e não as trabalhe isoladamente. Vários estudos têm-nos demonstrado que as quatro habilidades linguísticas não precisam ser ensinadas linearmente e tampouco se desenvolvem de maneira homogênea.

\section{Analisar o manual ou buscar alternativa para mudança?}

Há várias formas de abordar a avaliação do manual didático, Cunningsworth (Apud MORITA, 1998) ressalta que a melhor forma de analisar o manual é folhear e formar ideia geral das possibilidades, ou seja, observar os pontos fortes e fracos e, ao mesmo tempo, perceber características que se sobressaiam. Na concepção desse autor, essa é a prova mais coerente usada pelos professores quando se defrontam com novos manuais e a única que governa a escolha dos livros a serem usados em sala de aula. Outra forma de avaliação seria o que ele chama de avaliação em profundidade, ou seja, aquela que além de permitir ver o que é óbvio em um livro didático possibilita verificar, como item específico é trabalhado, em especial, aqueles que se relacionam às necessidades dos alunos, como diferentes aspectos da linguagem são trabalhados.

Contudo, ao analisar o manual devemos observar alguns critérios, primeiro deve-se observar se o público-alvo condiz com o material apresentado. Nesse item deve-se

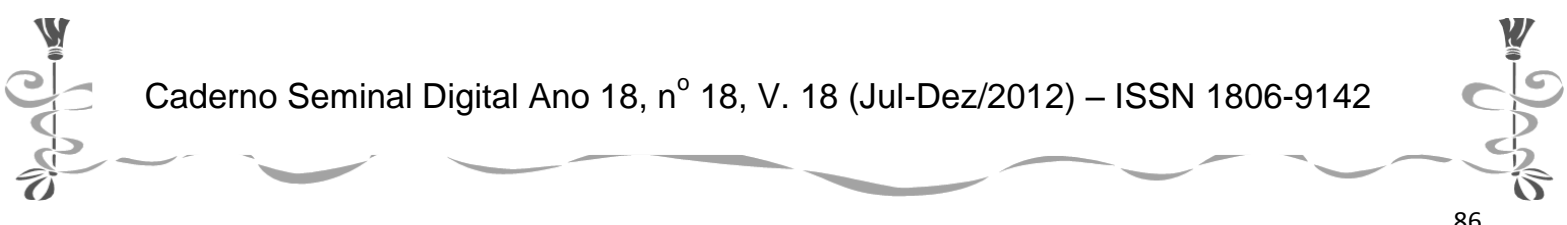




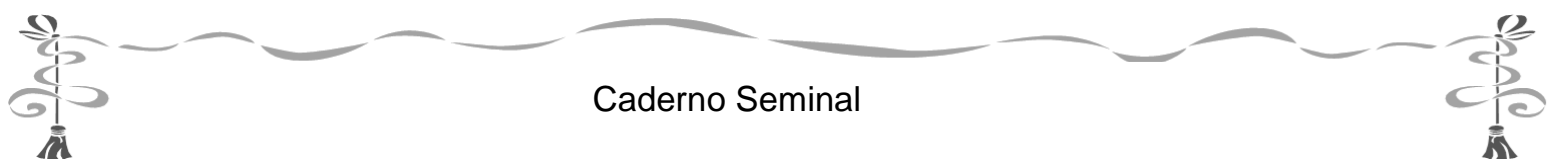

considerar: faixa etária, sexo, conhecimento de língua estrangeira e nível de formação.

Em segundo lugar, é preciso observar os objetivos que estão propostos no livro e se esses são alcançáveis ao longo das unidades do manual em questão. A linguagem é outro critério importante na análise, pois elas fundamentam as formas de ver e definir a linguagem e como são apresentados os conteúdos. A análise do conteúdo diz respeito não só à informação, mas à forma como ele é apresentado aos alunos e, também, aos tipos de conhecimento exigidos. É por meio dessa análise que observamos se as instruções são escritas de forma coerente, se os textos são adequados à faixa etária, interesse e nível de conhecimento dos alunos, se os tipos de atividade condizem com os demais elementos propostos.

Finalmente, o processo de análise de manuais termina com a implementação do curso. Ao usar um livro didático, deve-se pensar quais as adaptações precisam ser feitas, para o desenvolvimento do curso proposto.

\section{Avaliação dos livros didáticos}

Ramos (Apud RAMOS e ROSELI, 2003) apresenta alguns critérios para analisar o livro didático e direciona avaliando primeiro o público-alvo e se esse está adequado com o material apresentado. Para o autor, não se pode deixar de lado a idade, faixa etária, sexo, conhecimento de língua estrangeira e o nível de formação.

O outro critério é a adequação dos objetivos propostos apresentados no livro, observar se esses são executáveis e alcançados através dos textos, conteúdos e atividades apresentadas no decorrer das unidades do manual didático em questão.

Nessa linha de análise de critérios, acreditamos que as visões de linguagem são muito importantes, pois elas fundamentam as formas de ver e definir a linguagem e de que forma o conteúdo será apresentado nas unidades. Para nosso conforto, apoiamos nas três perspectivas de linguagem identificáveis em alguns livros didáticos citados por Cunningsworth (Apud MORITTA, 1998): 1) a perspectiva comunicativa - que a língua é vista como meio de comunicação entre as pessoas; 2) a perspectiva estrutural - não vê a língua como uma interação e sim, um sistema de gramática e vocabulário; 3) a perspectiva de habilidades - enfatiza as quatro habilidades: ouvir, falar, ler e escrever e finalmente acrescenta a perspectiva sociointeracionista que está contemplada pelos Parâmetros Curriculares Nacionais de Língua Estrangeira (Brasil, 1998, p.8), doravante PCN-LE, que novos olhares surgiram para o professor de línguas estrangeiras, com objetivos de ampliar o ensino da Língua Estrangeira e ao mesmo tempo oferecer teorias que contemplam a análise e seleção de materiais didáticos, de recursos tecnológicos e aporte contribuições para a formação profissional dos professores.

O desenvolvimento do ser humano se dá primeiro no nível social (interpessoal e depois no nível individual intrapessoal). Nessa linha de pensamento, podemos dizer

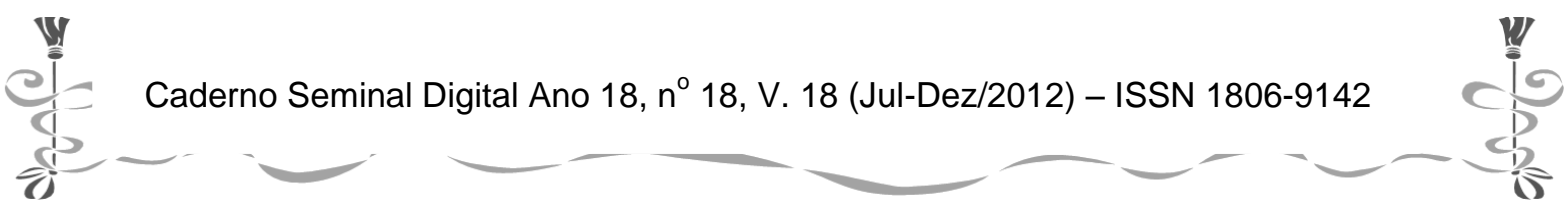




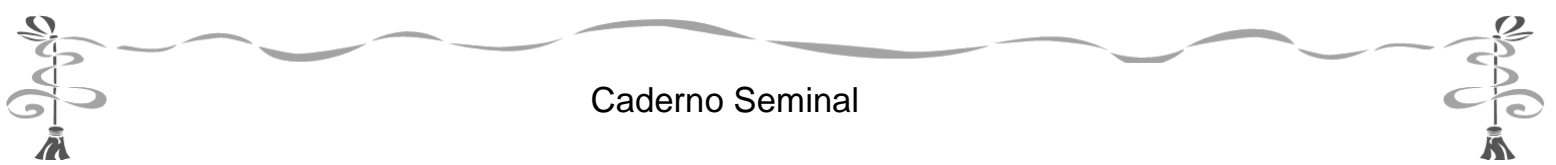

que aprender é uma forma de estar no contexto social interagindo com alguém em um contexto cultural, histórico e social. E isso se dá pela interação dialógica e pela ação do indivíduo.

Contudo, a aprendizagem de uma língua estrangeira vai muito mais além da aquisição e das habilidades linguísticas, pois "os indivíduos passam de meros consumidores passivos de cultura e de conhecimento a criadores ativos: o uso de uma língua estrangeira é uma forma de agir no mundo e transformá-lo" (BRASIL, 1998, p. 66).

\section{Observação dos livros didáticos}

Nessas observações acerca dos livros analisados faremos algumas abordagens e análise de dois livros para o ensino de Português como Língua Estrangeira: Avenida Brasil curso básico de Português para estrangeiros e o Bem-Vindo! A Lingua Portuguesa no Mundo da Comunicação Editora SBS. Foram escolhidos esses livros por ser os mais trabalhados na trajetória do ensino de PLE na UESC ${ }^{45}$.

O livro Avenida Brasil é organizado em doze lições que variam entre quatro a seis páginas cada lição reflete sobre temas relacionados a conhecer pessoas, encontros, comer e beber, hotel, cidade, moradia, corpo, trabalho, roupa, vida e família turismo e ecologia. Porém, os temas sejam diversificados carece de ser complementado por outros comandos no final das lições. Não consta material complementar para melhor auxiliar o que está posto nas lições. No final do livro consta um apêndice gramatical, uma tabela de conjugação de verbos regulares e irregulares, quadro geral do emprego dos tempos verbais e uma lista de vocabulário alfabético. Essa lista apresenta todas as palavras contidas nos diálogos, exercícios, textos e explicações gramaticais. Entretanto, a estrutura didática do livro não contempla o vocabulário dos textos de audição e leitura.

Ressaltamos que embora tenha uma visão estruturalista, o livro tem ajudado no decorrer das aulas, mas precisa de apoio didático e material complementar, seguida da estrutura das unidades e algumas sugestões para o roteiro de aula.

O segundo livro é Bem-Vindo! A língua portuguesa no mundo da comunicação, Português para Estrangeiros, edição atualizada distribuída em vinte unidades, cada unidade divida em subárea envolvendo temas do dia-a-dia. Esse livro traz temas mais envolventes, mais organizados em cerca de cinco páginas por unidade. Após cada unidade há uma revisão que as autoras denominaram Psiu! Diferente dos outros livros que existem no mercado brasileiro, existe material de apoio como: CD, livros para alunos de diferentes nacionalidades, o que complementa as atividades do aprendiz. As últimas unidades são referente a capoeira, carnaval, música popular e o folclore

\footnotetext{
${ }^{45}$ O programa de ensino de Português como Língua Estrangeira na Universidade Estadual de Santa Cruz, em Ilhéus-BA é reforçado por seminários, minicursos, além das pesquisas realizadas nas categorias Iniciação Científica e Mestrado.
}

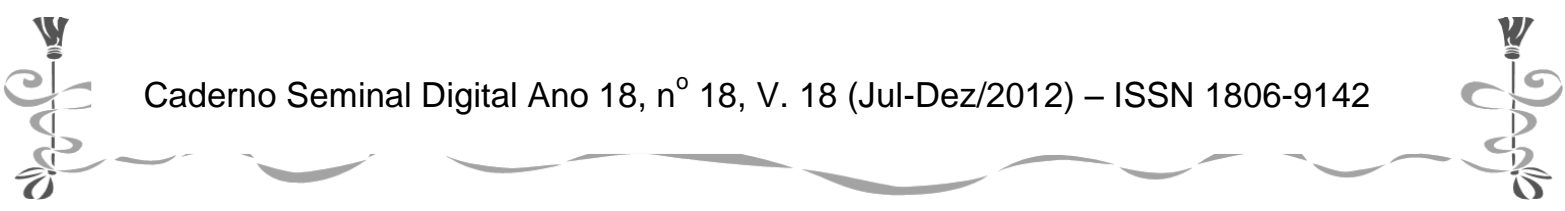




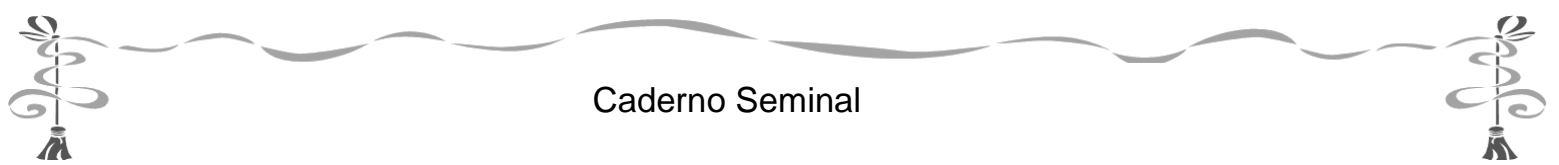

brasileiro, mas não há nada especificamente mais sobre a Bahia, lugar em que a pesquisa norteadora deste trabalho foi feita. Há também apêndice alfabético, gramatical e um apêndice de vocabulário enfatizando algumas profissões e algumas nacionalidades. A estrutura segue a teoria estruturalista, mas orienta com bastante clareza o professor na sala de aula, principalmente aquele que não tem muita experiência.

Para Cunningsworth (Apud MORITA, 1998), todos apresentam a mesma estrutura em relação ao número de unidades, à extensão das unidades, à organização por temas e por tipos de atividades. O quê falta nesses manuais é explicitar os objetivos de cada unidade, contextualizar o vocabulário, pois se percebe a descontextualizarão nos dois livros analisados que não apresentam nenhum contexto discursivo. Particularmente, em situações sociais, o que se observa da metodologia utilizada, principalmente na Avenida Brasil, é o exercício de repetição, memorização e fixação que visam à aquisição principalmente de vocabulário descontextualizado. Aqui presenciamos a visão tradicionalista de aprendizagem, pela qual se acredita que é possível modelar o indivíduo, utilizando os estímulos adequados. Urge a necessidade de ampliar os exercícios que trabalhem músicas, jogos, internet para que essas diversidades possam complementar as atividades dos alunos

\section{Algumas considerações}

No decorrer da análise ficou latente a pouca interação entre os alunos e o manual didático. Se considerarmos a interação social a interface do desenvolvimento e aprendizagem, nesses manuais avaliados sugerimos ao professor que ao adotar um dos materiais acima mencionados, complemente com atividades que permitam essa experiência. $O$ processo de aprendizagem mediado pela interação é o que leva à construção de um conhecimento conjunto entre os pares dessa interação. Nos manuais analisados, observa-se uma prática mecanicista e descontextualizada de vocabulário e estruturas gramaticais.

Contudo, devemos ressaltar que o manual é um recurso imprescindível no contexto escolar. Sendo assim, é considerado por alguns professores como ferramenta principal e por alguns alunos principalmente os estrangeiros quando esses não estão no contexto de imersão. Entretanto, os questionamentos apresentados nesse trabalho mostram que o manual não é o único caminho. Aqui não consideramos nada no plano superior do que a interação aluno/professor na contraposição ao conhecimento. A sugestão de apresentar situações cotidianas o mais próximo do real para que o processo ensino-aprendizagem se efetive de forma agradável e que possibilite ao aprendiz a vivenciar em língua estrangeira situações de aprendizagem que sejam significativas e que, principalmente a situem no contexto em que vive, visando um desenvolvimento no processo de ensino aprendizagem.

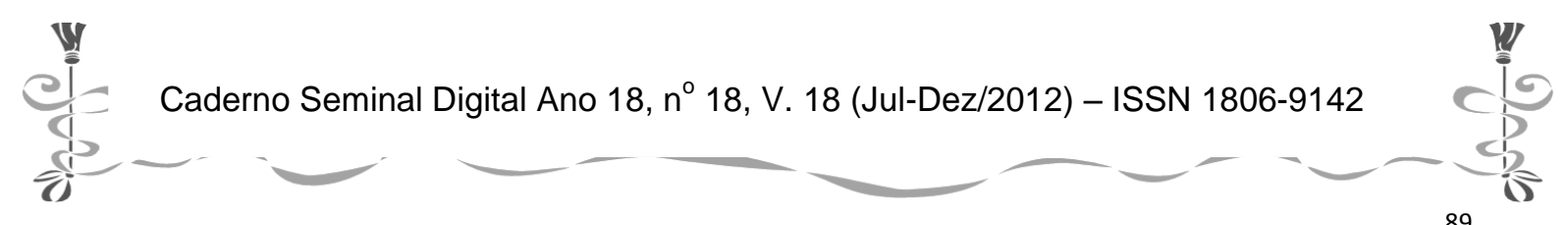




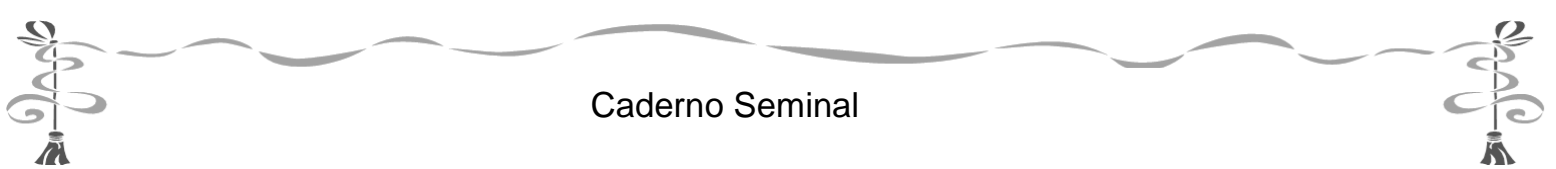

\section{Referências}

ABRAHÃO, M. H. V. Metodologia na investigação das crenças. In: BARCELOS, A. M. F; Crenças e Ensino de Linguas: Foco no professor, no aluno e na formação de professores. São Paulo, Campinas: Pontes Editores, 2006.

ALMEIDA FILHO, José Carlos Paes de. O ensino de Português para Estrangeiros nas Universidades Brasileiras. In: ALMEIDA FILHO, José Carlos Paes de; LOMBELLO, Leonor. (Orgs.) Identidade e caminhos no Ensino de Português para Estrangeiros. Campinas, SP: Pontes, 1992.

BRASIL, Ministério da Educação e do Desporto. Parâmetros Curriculares Nacionais - Linguas Estrangeiras. Brasília, MEC/SEF, 1998.

BRITO, Ana Pacheco. A problemática da adopção dos manuais escolares, Critérios e reflexões. In: Actas - Manuais Escolares- estatuto, funções, história. Instituto de Educação e Psicologia: Universidade do Minho, 1999.

GOMES DE MATOS, Francisco. A criatividade de aprendizes de português e de línguas estrangeiras. In: ALENCAR, Eunice; VIRGOLIM, Angela (org.). Criatividade, Expressão, Desenvolvimento. Petrópolis: Vozes, 1994.

HUOT, Hélène. Dans la jungle des manuels scolaires. Paris: Éditions du Seuil, 1989.

LIMA, Emma Eberlein O. F.; ROHRMANN, Lutz; ISHIHARA, Tokiko. Avenida Brasil: curso básico de Português para estrangeiros. São Paulo, SP: Editora E.P.U., 1991.

MORITA, Marisa Kimie. (Re) pensando sobre o material didático de PLE. In: SILVEIRA, Regina Célia P. da. (org.). Português Lingua Estrangeira: perspectivas. São Paulo: Cortez Editora, 1998.

MOTA, K. M. S. Incluindo as diferenças, resgatando o coletivo - novas perspectivas multiculturais no ensino de línguas estrangeiras. In: MOTA K. \& SCHEYERL, D. Recortes interculturais na sala de aula de linguas estrangeiras (orgs.). Salvador: EDUFBA: Instituto de Letras, Departamento de Letras Germânicas, 2004.

PACHECO, Denise Gomes Leal Cruz. Português para estrangeiros e os matérias didáticos: um olhar discursivo. Rio de Janeiro: Editora. 2006.

PONCE, Maria Harumi Otuki de; BURIM, Silvia R. B. Andrade; FLORISSI, Susanna. BemVindo! A Lingua Portuguesa no mundo da comunicação - Reposta aos Exercícios. São Paulo: SBS, 2007.

SCHON, Donald. Os professores e sua formação. Lisboa: Dom Quixote, 1997.

RAMOS, Rosinda de Castro Guerra Ramos.; ROSELLI, Bernadette Rodrigues. O livro didático e o ensino-aprendizagem de inglês para crianças. In: ROCHA, Cláudia Hilsdorf.; BASSO, Edcleia Aparecida. Ensinar e aprender lingua estrangeira nas diferentes idades: reflexões para professores e formadores. São Carlos-SP: Claraluz, 2008.

TAVARES, Ana. Ensino/Aprendizagem do Português como Lingua Estrangeira. In: GROSSO, Maria José. (org.) Lisboa: Lidel, 2008.

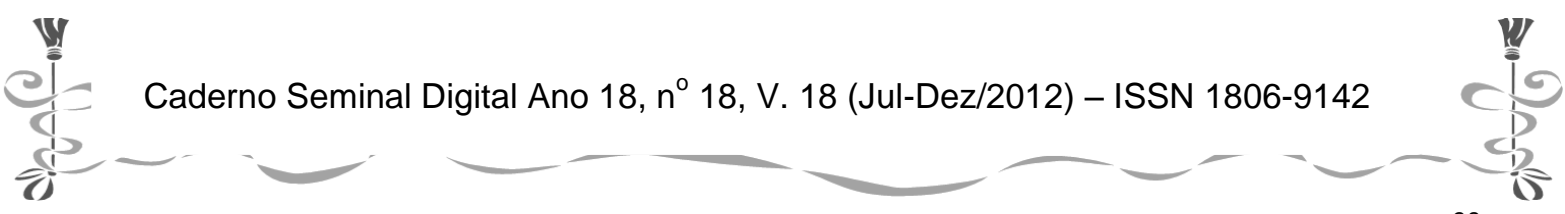

